\title{
Formation of the bow shock indentation: MHD simulation results
}

\author{
BaoHang Qu', JianYong Lu' ${ }^{1 *}$, Ming Wang ${ }^{1}$, HuanZhi Yuan ${ }^{1,2}$, Yue Zhou', and HanXiao Zhang ${ }^{1}$ \\ ${ }^{1}$ Institute of Space Weather, School of Math \& Statistics, Nanjing University of Information Science \& Technology, Nanjing 210044, China; \\ ${ }^{2}$ Key Laboratory of Earth and Planetary Physics, Institute of Geology and Geophysics, Chinese Academy of Sciences, Beijing 100029, China
}

Key Points:

- Confirm the indentation of bow shock.

- Analyze the formation conditions of the bow shock indentation.

- Investigate the physical mechanism of the bow shock indentation.

Citation: Qu, B. H., Lu, J. Y., Wang, M., Yuan, H. Z., Zhou, Y. and Zhang, H. X. (2021). Formation of the bow shock indentation: MHD simulation results. Earth Planet. Phys., 5(3), 259-269. http://doi.org/10.26464/epp2021033

\begin{abstract}
Simulation results from a global magnetohydrodynamic (MHD) model are used to examine whether the bow shock has an indentation and characterize its formation conditions, as well as its physical mechanism. The bow shock is identified by an increase in plasma density of the solar wind, and the indentation of the bow shock is determined by the shock flaring angle. It is shown that when the interplanetary magnetic field (IMF) is southward and the Alfvén Mach number $\left(M_{a}\right)$ of solar wind is high $(>5)$, the bow shock indentation can be clearly determined. The reason is that the outflow region of magnetic reconnection (MR) that occurs in the low latitude area under southward IMF blocks the original flow in the magnetosheath around the magnetopause, forming a high-speed zone and a low-speed zone that are upstream and downstream of each other. This structure hinders the surrounding flow in the magnetosheath, and the bow shock behind the structure widens and forms an indentation. When $M_{a}$ is low, the magnetosheath is thicker and the disturbing effect of the MR outflow region is less obvious. Under northward IMF, MR occurs at high latitudes, and the outflow region formed by reconnection does not block the flow inside the magnetosheath, thus the indentation is harder to form. The study of the conditions and formation process of the bow shock indentation will help to improve the accuracy of bow shock models.
\end{abstract}

Keywords: indentation of bow shock; global MHD simulation; interplanetary magnetic field $B_{z}$; Alfvén Mach number

\section{Introduction}

Solar wind plasma can be regarded as a magnetic fluid with infinite conductivity, and it surrounds the Earth's magnetic field, which forms the magnetosphere. In order to produce a circumfluence around the Earth's magnetosphere, the super-Alfvenic solar wind has to reduce its velocity, generating a bow shock upstream of the magnetopause. The shape and size of the bow shock are controlled by many factors, such as the upstream solar wind parameters, the flow inside the magnetosheath, and the position of the magnetopause (e.g., Farris and Russell, 1994; Verigin et al., 2001a, 2001 b; Chao JK et al., 2002; Chapman and Cairns, 2003; Dmitriev et al., 2003; Merka et al., 2005; Lu JY et al., 2019a). The upstream solar wind parameters include solar wind dynamic pressure $\left(P_{d}\right)$, Mach number, and the direction and intensity of the IMF. In addition, many studies have developed bow shock models using global MHD simulations or satellite observation data (e.g., Spreiter et al., 1966; Fairfield, 1971; Formisano, 1979; Němeček and Šafránková, 1991; Farris and Russell, 1994; Cairns and Lyon, 1995; Peredo et al., 1995; Chapman and Cairns, 2003; Lu JY et al., 2019a).

Correspondence to: J. Y. Lu, jylu@nuist.edu.cn

Received 20 NOV 2020; Accepted 26 APR 2021.

Accepted article online 10 MAY 2021.

(C)2021 by Earth and Planetary Physics.
The north-south component of the IMF $\left(B_{z}\right)$ has an important influence on the bow shock. For example, when IMF is southward, the solar wind-magnetosphere generates energy coupling through MR on the dayside (Song P et al., 2001), resulting in energy and particle injection into the cusp of the magnetosphere (Gonzalez et al., 1994). Lu JY et al. (2019b) found that the high magnetosheath density flows downstream along the magnetopause and there are open magnetic field lines at both high and low latitudes of the magnetopause, when the IMF turns from north to south. The solar wind azimuthal and northward/southward flows are significant dynamic drivers of the cusp (Zong QG et al., 2004). In addition, MR at the high-latitude magnetopause can result in some regions where solar wind enters into the Earth's high-latitude magnetopause tailward of the cusps (Shi QQ et al., 2013). Zong QG et al. (2018) also investigate the electron diffusion region of $M R$ in the high-latitude magnetopause when the IMF is northward. When southward IMF increases, the reconnection rate will increase and the magnetopause will be closer to the Earth (e.g., Xiong M et al., 2009; Wang J et al., 2018). Also, under a southward IMF, the position of the subsolar bow shock does not change significantly, but the flaring angle of the bow shock will increase with $B_{z}$ magnitude (Hu HP et al., 2015). For northward IMF, MR will occur at high latitudes (Song $P$ et al., 1999). During 
northward IMF, plasmas of the solar wind can transport to the magnetosphere via high-latitude dual-lobe reconnection (Shi QQ et al., 2009). With increasing northward IMF $\left(B_{z}\right)$, the subsolar bow shock moves further away from the Earth and the flaring angle also increases (Hu HP et al., 2015).

The east-west $\left(B_{y}\right)$ and radial $\left(B_{x}\right)$ components of the IMF are important factors that affect the bow shock position. The eastward direction of the IMF $\left(B_{y}>0\right)$ will affect the position of the subsolar bow shock, and the cross-section of the bow shock tail will be elongated in the direction perpendicular to the IMF (Wang M et al., 2016, 2018). The influence of IMF $B_{x}$ on the bow shock is mainly on the shock asymmetry (Cowley, 1981). When the IMF contains both $B_{y}$ and $B_{x}$ IMF $B_{x}$ will cause north-south asymmetry of the bow shock in the meridional plane. As IMF $B_{x}$ increases (magnetosonic Mach number becomes larger), the northern part of the bow shock moves closer to the Earth, while the situation in the southern hemisphere is just the opposite (Wang J et al., 2020).

In addition to the effects of IMF components, $P_{d}$ and Mach number influence on the bow shock also plays an important role. Most studies have shown that when $P_{d}$ increases, the subsolar bow shock moves toward Earth, and the shock's flaring angle decreases accordingly (e.g., Chao JK et al., 2002; Jelínek et al., 2012; Shi QQ et al., 2014). However, some also suggest that $P_{d}$ cannot describe the structure of the bow shock tail very well (Dmitriev et al., 2003). In addition, most studies posit that the size of the bow shock will decrease as the fast magnetosonic Mach number $\left(M_{\mathrm{ms}}\right)$ increases (e.g., Farris and Russell, 1994; Verigin et al., 2001a; Chao JK et al., 2002). In contrast, Merka et al. (2005) propose that the decrease in the $M_{a}$ can cause the bow shock to expand outward.

The dipole tilt angle is another factor that affects the bow shock. For example, using observation data, Merka and Szabo et al. (2004) find that under average solar wind conditions when the dipole tilt angle changes from positive to negative, the magnetic tail of the bow shock between 10 and $15 R_{\mathrm{E}}$ (the radius of the Earth) shifts about $3.8 R_{\mathrm{E}}$ in the north-south direction. Lu JY et al. (2017) statistically analyzed observational data of the bow shock and found that the distance of the subsolar bow shock increases with the dipole tilt angle; this trend is more obvious when the dipole tilt angle is negative. Moreover, it was also found that an increase of the dipole tilt angle leads to a decrease in the flaring angle of the bow shock tail. When the dipole tilt angle changes from negative to positive, the bow shock shifts Earthward. Wang $M$ et al. (2015) further pointed out that an increase of the dipole tilt angle will lead to increased distance between the bow shock and the north-south asymmetry. Subsequently, Lu JY et al. (2019a) developed a three-dimensional asymmetric bow shock model incorporating the dipole tilt angle.

Finally, some studies maintain that the bow shock is closely related to the magnetopause (e.g., Farris and Russell, 1994; Verigin et al., 2001a). The shock stands further away from a blunt obstacle than it does from a sharp obstacle, and the thickness of the magnetosheath decreases accordingly. These works use the radius of curvature of the magnetopause and the subsolar magnetopause distance as the main parameters for their bow shock model (e.g., Farris and Russell, 1994; Cairns and Lyon, 1995). Since the mag- netopause has a clear cusp, it is natural to speculate a similar indentation in the bow shock corresponding to the cusp; a statistical study of observational data by Jelínek et al. (2008) suggested such an indentation. However, whether this indentation exists, how and under what kinds of conditions it is generated, and the indentation size are all unclear. The purpose of this work is to use global three-dimensional MHD simulations to verify the bow shock indentation under different solar wind conditions and explain the generation mechanism. Section 2 introduces the MHD data used in the article and the method to determine the bow shock configuration. Section 3 introduces the process for verifying the existence of the bow shock indentation and the reason for its formation. Section 4 gives the conclusion and summary.

\section{Data and Model}

The Space Weather Modeling Frame (SWMF) is a physical model established by the University of Michigan and has been widely used in various processes of the interaction between the interplanetary solar wind and a planetary magnetosphere (Tóth et al., 2005). Numerous validation studies of SWMF have been performed (e.g., Song P et al., 1999; Gombosi et al., 2000; Kabin et al., 2004; Tóth et al., 2007; Rae et al., 2010). We also used the SWMF model to study many phenomena such as the magnetopause model (e.g., Lu JY et al., 2011, 2013; Liu ZQ et al., 2012, 2015), magnetopause energy transmission (Jing $\mathrm{H}$ et al., 2014), and the bow shock model (e.g., Wang M et al., 2015, 2016). In the current study, two sets of MHD data are used to profile the bow shock under different IMF conditions, as shown in Table 1. The computational domain of data group $\mathrm{A}$ is chosen as $-70 R_{\mathrm{E}} \leq X \leq 20 R_{\mathrm{E}},-60 R_{\mathrm{E}} \leq(Y, Z)$ $\leq 60 R_{E}$ in GSM coordinates. The grid size of data group $A$ is as follows : $0.3125 R_{\mathrm{E}}$ in the area where $-25 R_{\mathrm{E}} \leq X \leq 12.5 R_{\mathrm{E}}$ and $-30 R_{\mathrm{E}} \leq$ $(Y, Z) \leq 30 R_{\mathrm{E}} ; 0.625 R_{\mathrm{E}}$ in the area where $-40 R_{\mathrm{E}} \leq X \leq 20 R_{\mathrm{E}}$ and $-45 R_{\mathrm{E}} \leq(Y, Z) \leq 45 R_{\mathrm{E}}$; and $1.25 R_{\mathrm{E}}$ in other areas. The computational domain of data group $\mathrm{B}$ is defined by $-40 R_{\mathrm{E}} \leq X \leq 20 R_{\mathrm{E}},-40 R_{\mathrm{E}} \leq(Y$, $Z) \leq 40 R_{E}$ in GSM coordinates. The grid size of data group $B$ is as follows: $0.25 R_{\mathrm{E}}$ in the area where $-5 R_{\mathrm{E}} \leq X \leq 15 R_{\mathrm{E}}$ and $-20 R_{\mathrm{E}} \leq(Y, Z)$

Table 1. The grouping information of MHD data.

\begin{tabular}{|c|c|c|}
\hline Group & Data group A & Data group B \\
\hline IMF $B_{x}(\mathrm{nT})$ & 0 & 0 \\
\hline IMF $B_{y}(\mathrm{nT})$ & 0 & 0 \\
\hline IMF $B_{Z}(\mathrm{nT})$ & $\pm 5, \pm 10$ & $\begin{array}{c}-2.5,-5,-7.5,-10 \\
-15,-20,-25\end{array}$ \\
\hline$P_{d}(\mathrm{nPa})$ & $1,3,5$ & 2 \\
\hline Density $\left(\mathrm{amu} / \mathrm{cm}^{3}\right)$ & $5,7.1745,11.9574$ & 6 \\
\hline$V_{x}(\mathrm{~km} / \mathrm{s})$ & -345.795 & -450 \\
\hline$V_{y}(\mathrm{~km} / \mathrm{s})$ & 0 & 0 \\
\hline$V_{z}(\mathrm{~km} / \mathrm{s})$ & 0 & 0 \\
\hline $\begin{array}{l}\text { Dipole tilt angle } \\
\quad(\mathrm{rad})\end{array}$ & 0 & 0 \\
\hline Coordinate system & GSM & GSM \\
\hline $\begin{array}{c}\text { Computational } \\
\text { domain }\end{array}$ & $\begin{array}{c}\text { Computational } \\
\text { domain } 1\end{array}$ & $\begin{array}{l}\text { Computational } \\
\text { domain } 2\end{array}$ \\
\hline
\end{tabular}


$\leq 20 R_{\mathrm{E}}$ and $0.5 R_{\mathrm{E}}$ in other areas. Note that the dipole tilt angle is zero in this work.

The effective determination of the bow shock is the basis of the entire study. During the process of the solar wind passing through the bow shock and entering the magnetosheath, the solar wind plasma density and magnetic field strength are significantly increased, while the solar wind speed will decrease. Therefore, the following identification methods are used in this work:

(1) Perform linear interpolation on the original data so that resolution in the $Y Z$ plane is constant under the same $X$ value;

(2) Take a slice parallel to the $Z Y$ plane for each value of $X$. Then, the slice is divided into four regions, where the direction of the index in one region is different from those in other regions, depicted by the arrow in Figure 1. In each indexing process, we denote the bow shock as the location where the plasma density slope reaches its first extreme value;

(3) Finally, perform step (2) for all slices.

Figure 2 shows the position of the bow shock obtained by the above method under IMF $B_{z}=-5 \mathrm{nT}$ and $P_{d}=1 \mathrm{nPa}$. Figure 2a depicts the position of the bow shock in three dimensions. Figure 2b, 2c, and 2d show the position of the bow shock in the $X Y, X Z$, and $Y Z$ planes (black point), where the background color indicates the plasma density. It can be found in Figure 2 that there is sparse data near the subsolar bow shock, due to the data resol- ution and indexing method. However, this work focuses on the bow shock indentation and the sparse region does not affect our results.

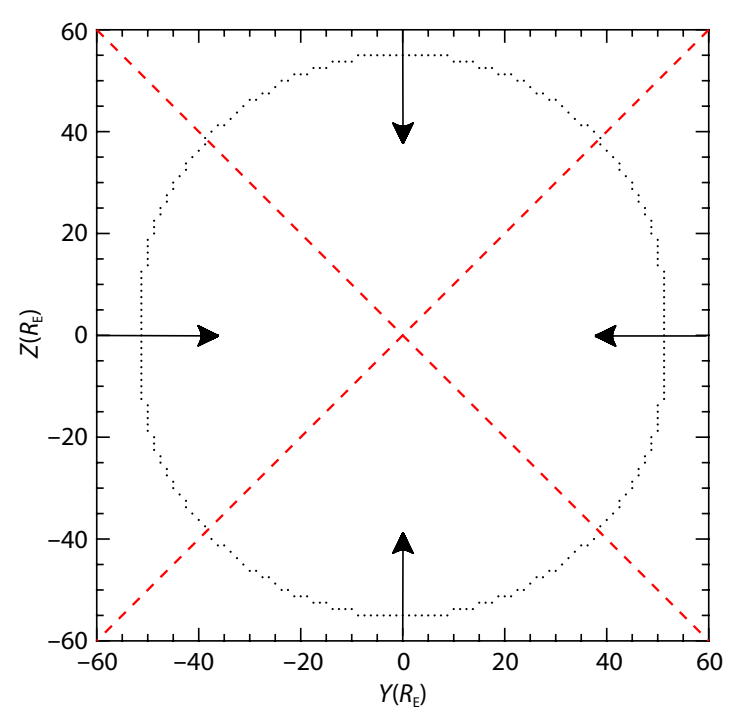

Figure 1. Bow shock slice parallel to the $Z Y$ plane. The arrow indicates the direction of indexing. The black spots are the location of the bow shock at $x=-45 R_{\mathrm{E}}$ for $B_{z}=-5 \mathrm{nT}$ and $P_{d}=1 \mathrm{nPa}$.
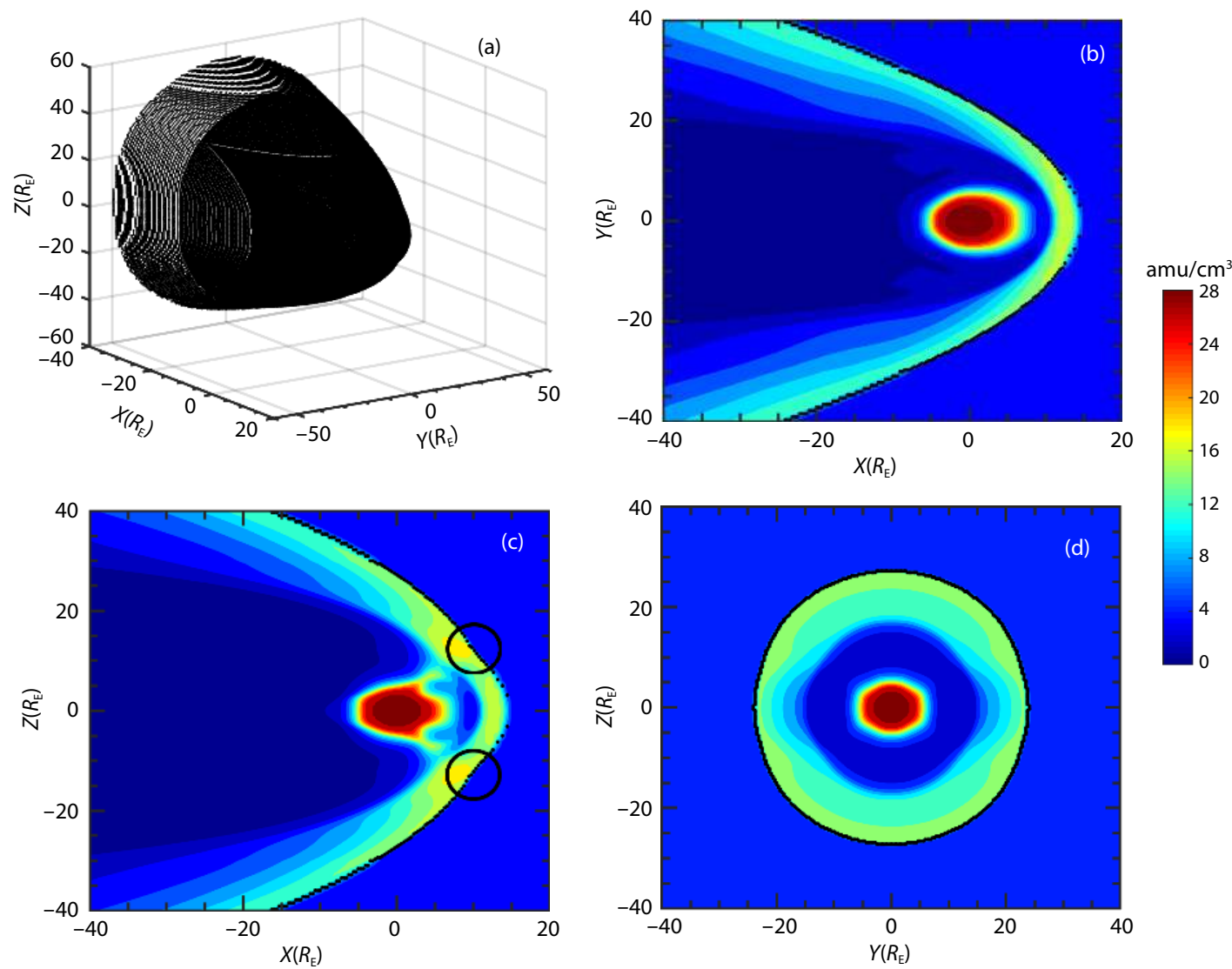

Figure 2. The identified bow shock for $B_{z}=-5 \mathrm{nT}$ and $P_{d}=1 \mathrm{nPa}$. (a) the three-dimensional shape of the bow shock, and plasma density contour plot of the (b) equatorial bow shock, (c) meridional bow shock, and (d) bow shock cross-section at $X=0 R_{\mathrm{E}}$. The black spots mark the bow shock and the black circle in (c) indicates the indentation site. 


\section{Results}

Following the bow shock determination method, it can be clearly identified in Figure $2 c$ where the black circle represents the indentation sites. In order to show the bow shock indentation more clearly, we first parameterized the configuration of the bow shock. It has been demonstrated that the parabola formula suggested by Shue JH et al. (1997) is well-suited to describe the magnetopause and bow shock (e.g., Shue JH et al., 1997; Lu JY et al., 2019a). This formula is as follows:

$$
\begin{gathered}
r=r_{0}\left(\frac{2}{1+\cos \theta}\right)^{a}, \\
\theta=\cos ^{-1}\left(\frac{X}{r}\right), \\
r=\sqrt{X^{2}+Y^{2}+Z^{2}},
\end{gathered}
$$

where, $r$ is the distance from the bow shock to the center of the Earth, $\theta$ is the angle between the position of the bow shock and the line between the sun and the Earth, $r_{0}$ is the distance of the subsolar bow shock, and $a$ is the flaring angle parameter of the bow shock. $(X, Y, Z)$ is the position of the bow shock in the GSM coordinate system. In addition, the flaring parameter $(a)$ indicates the level of shock flaring, where a decrease of $a$ indicates that the bow shock contracts to the interior. The flaring angle parameter $a$ of each point on the bow shock surface can be calculated by the coordinates $(X, Y, Z)$ and $r_{0}$ can be obtained in the MHD data. When solar wind conditions are the same, the shape of the bow shock is stable and $a$ is the same in each position of the bow shock without any indentation. However, if there is an indentation, the flaring in the indentation region will be smaller than that in other areas due to the indentation. Therefore, through the distribution of $a$, the indentation can be clearly observed.

First, we need to smooth the bow shock data for the $Y Z$ plane. Second, we identify the suitable position of the subsolar bow shock. Since the index method usually cannot identify the exact location of the subsolar bow shock, we have to use another method, i.e. finding the first extreme of the plasma density slope on the negative $X$-axis. Then, the $a$ of each position is calculated by the above formula, and Figure 3 displays the calculation results.

Figure $3 \mathrm{a}$ and $3 \mathrm{c}$ are the distribution of $a$ in the northern hemisphere under $B_{z}=10 \mathrm{nT}$ and $P_{d}=3 \mathrm{nPa}$. From Figure $3 \mathrm{a}$, it can be found that $a$ increases with the absolute value of $Y$. Figure $3 c$ shows that $a$ slightly decreases with $X$ at the magnetic tail and steeply increases with $X$ near the subsolar point. Figure $3 b$ and $3 d$ are the distribution of $a$ in the northern hemisphere under $B_{z}=$ $-10 \mathrm{nT}$ and $P_{d}=3 \mathrm{nPa}$. Comparing Figure $3 \mathrm{~b}$ and $3 \mathrm{a}$, there is a very obvious minimum area in the dayside bow shock. In addition, the trend of $a$ in Figure $3 d$ is different from that in Figure 3c. Figure $3 \mathrm{~d}$ shows that there is a steeply decreasing region near $X=$ $8 R_{\mathrm{E}}$, caused by the minimum value region in Figure $3 \mathrm{~b}$ (e.g. the indentation of the bow shock). Next, we find that the indentation of the northern hemisphere is symmetrical to that in the southern hemisphere, so we don't need to specifically study the the latter. In addition, a similar comparison is performed for bow shocks under other interplanetary conditions, and it is found that the steep and large decrease of $a$ is suitable to identify the indentation. Table 2 denotes the minimum of $a$ for each interplanetary condition. In this work, we use the following definition to identify a bow shock indentation: the indentation occurs when the difference
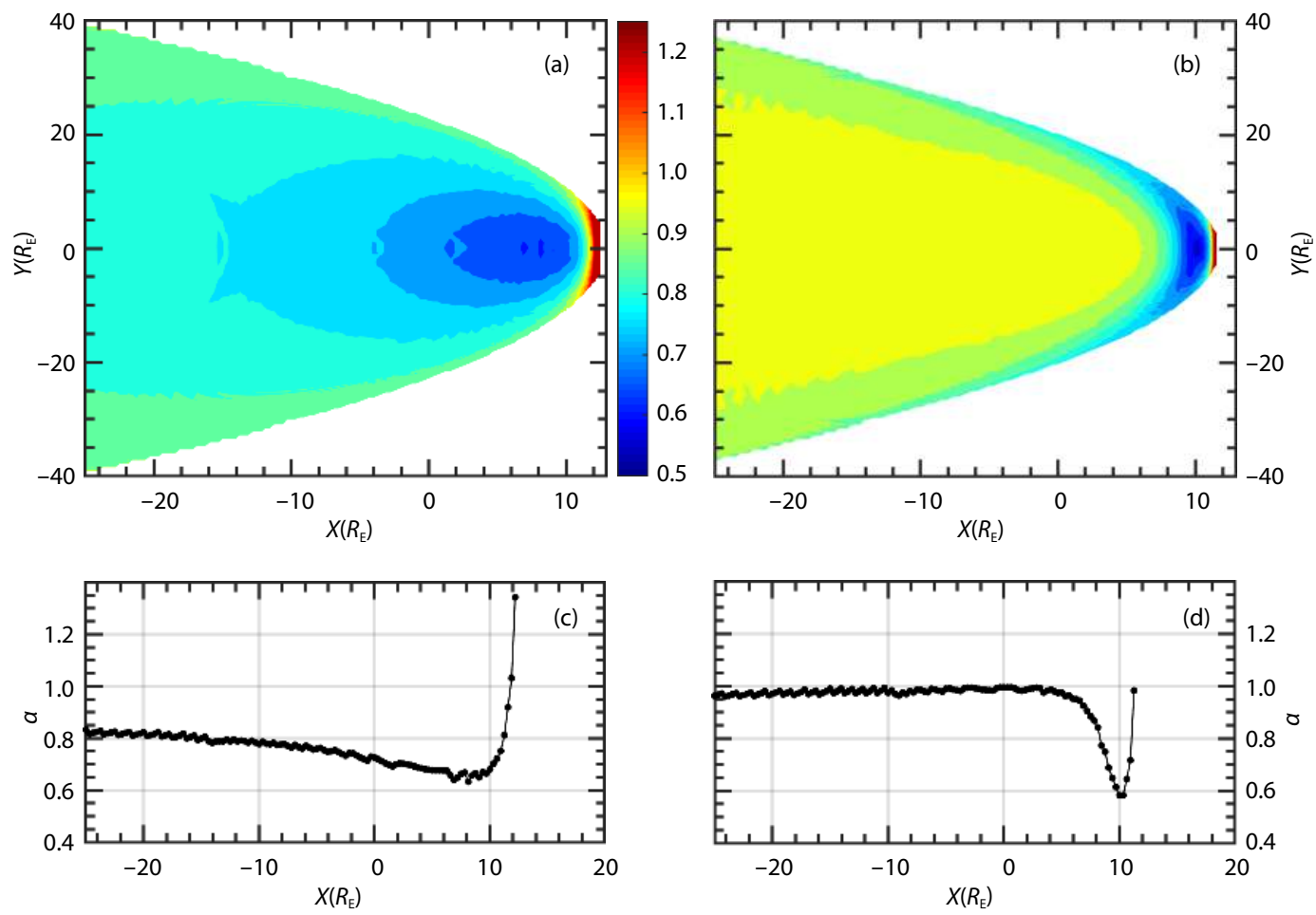

Figure 3. The calculated $a$ for $B_{z}=10 \mathrm{nT}, P_{d}=3 \mathrm{nPa}$ (left) and $B_{z}=-10 \mathrm{nT}, P_{d}=3 \mathrm{nPa}$ (right). The background color represents $a$ of the northern hemisphere in (a) and (b). (c) and (d) show variation of $a$ with $X$ in the northern hemisphere when $Y=0$. 
between the minimum and the average $a(0 \leq X \leq 5)$ is greater than 0.3 .

By performing the above method for all MHD data, the results are shown in Table 2. The results of data group A show the bow shock indentation will occur when the IMF is southward, but there is no indentation under $B_{z}=-10 \mathrm{nT}$ and $P_{d}=1 \mathrm{nPa}$. This may be related to the value of $M_{\alpha}$. Consequently, $M_{a}$ of various interplanetary conditions is calculated, and the results show that $M_{\alpha}$ is lowest in data group $A$ when the indentation does not exist. In order to enhance the accuracy of this conclusion, the same calculation for data group $A$ is performed on data group $B$. The conclusion of data group $B$ indicates that the indentation will exist when $M_{a}$ is greater than 5. From the statistical results of the bow shock indentation, it can be found that the indentation can be clearly observed when the IMF is southward and $M_{a}$ is high ( $>5$ ).

How is this bow shock indentation generated? Figures 4 and 5 show the $X Z$ plane under $B_{z}=-5 \mathrm{nT}$ and $P_{d}=1 \mathrm{nPa}$, where the arrow in Figure 4 represents the flow direction while the curve in Figure 5 represents the magnetic field lines. The colored background represents $\left|V_{\text {total }}\right|$ which is $\sqrt{\left(V_{X}\right)^{2}+\left(V_{Z}\right)^{2}}$, and the right panel of Figures 4 and 5 is an enlargement of the black frame on the left side of each figure, respectively. In the black frame of Figure 4, it can be found that there is a region of extreme velocity plasma near $X=8 R_{\mathrm{E}}$ and $Z=7 R_{\mathrm{E}}$ (marked with an asterisk), and the mag-

Table 2. The calculated results of $M_{a}$ for various conditions.

\begin{tabular}{|c|c|c|c|c|c|c|c|c|c|}
\hline \multicolumn{5}{|c|}{ Data group A } & \multicolumn{5}{|c|}{ Data group B } \\
\hline IMF $B_{z}(\mathrm{nT})$ & $P_{d}(\mathrm{nPa})$ & $M_{\alpha}$ & Minimum of $\alpha$ & Indentation & IMF $B_{z}(\mathrm{nT})$ & $P_{d}(\mathrm{nPa})$ & $M_{\alpha}$ & Minimum of $\alpha$ & Indentation \\
\hline 10 & 1 & 3.54 & 0.50 & No & -2.5 & 2 & 20.19 & 0.19 & Exist \\
\hline 10 & 3 & 6.13 & 0.63 & No & -5 & 2 & 10.09 & 0.45 & Exist \\
\hline 10 & 5 & 7.92 & 0.42 & No & -7.5 & 2 & 6.73 & 0.57 & Exist \\
\hline 5 & 1 & 7.08 & 0.63 & No & -10 & 2 & 5.04 & 0.65 & Exist \\
\hline 5 & 3 & 12.27 & 0.51 & No & -15 & 2 & 3.36 & 0.97 & No \\
\hline 5 & 5 & 15.84 & 0.60 & No & -20 & 2 & 2.52 & 0.93 & No \\
\hline-10 & 1 & 3.54 & 0.88 & No & -25 & 2 & 2.02 & 1.03 & No \\
\hline-10 & 3 & 6.13 & 0.58 & Exist & & & & & \\
\hline-10 & 5 & 7.92 & 0.41 & Exist & & & & & \\
\hline-5 & 1 & 7.08 & 0.27 & Exist & & & & & \\
\hline-5 & 3 & 12.27 & 0.41 & Exist & & & & & \\
\hline-5 & 5 & 15.84 & 0.47 & Exist & & & & & \\
\hline
\end{tabular}

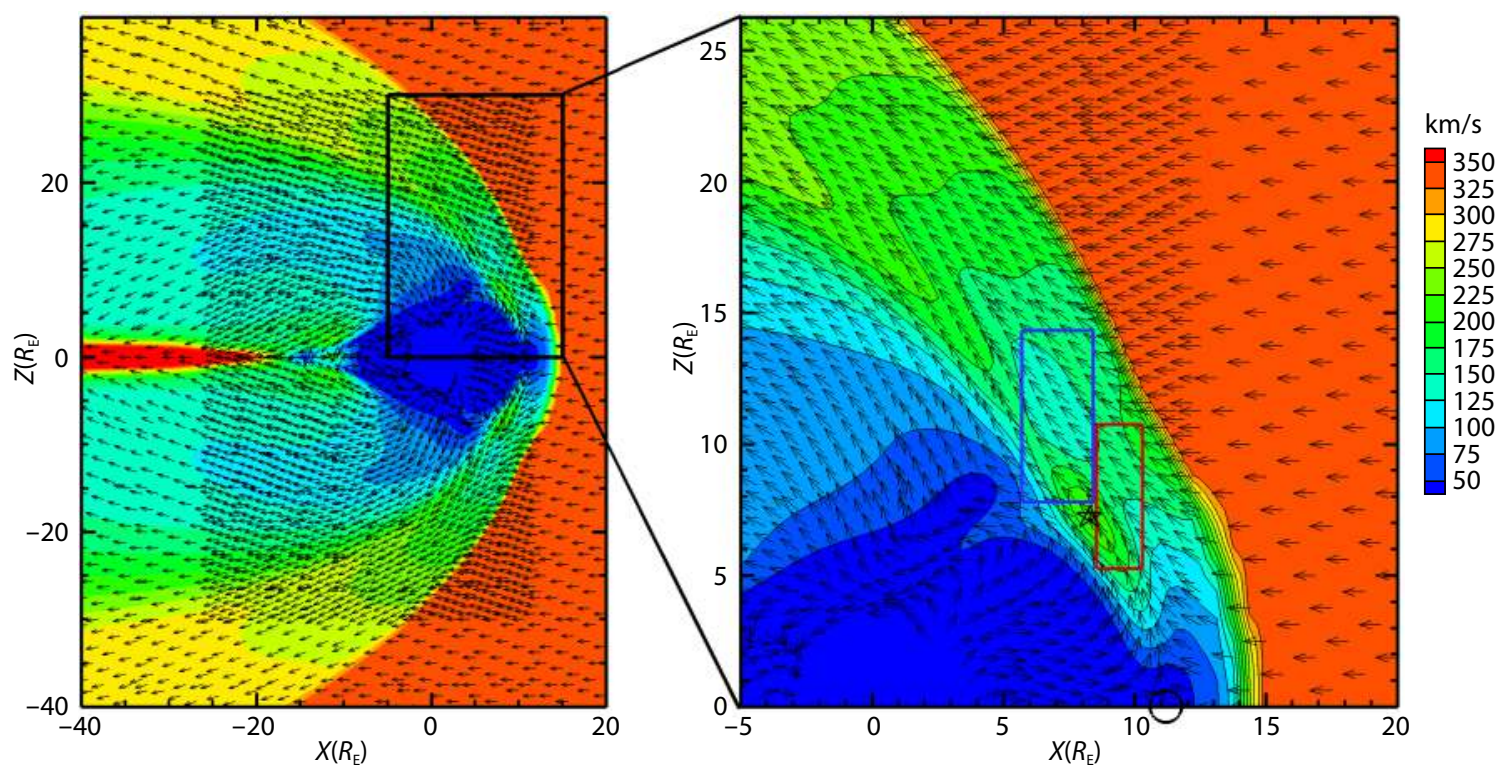

Figure 4. The plasma speed and flow direction in the meridional plane under $B_{z}=-5 \mathrm{nT}$ and $P_{d}=1 \mathrm{nPa}\left(M_{\alpha}=7.08\right)$. The colored background denotes $\left|V_{\text {total }}\right|\left(\left|V_{\text {total }}\right|=\sqrt{\left(V_{X}\right)^{2}+\left(V_{Z}\right)^{2}}\right)$ and the arrows indicate the direction of flow. The right panel is an enlargement of the black frame for the left panel. The blue frame in the right panel represents the low-speed zone and the red frame represents the high-speed zone. The black circle in the right panel indicates the reconnection site. 
netic field lines in Figure 5 illustrate that this phenomenon is caused by the outflow region of the MR (marked with a black circle). In the absence of a disturbance, the plasma slows down along the flow direction at low latitudes of the magnetosheath, while the plasma becomes faster along the flow direction in other regions of the magnetosheath. However, the high-speed plasma in the outflow region formed by MR disturbs the flow inside the magnetosheath, forming a high-speed zone (red frame) and a low-speed zone (blue frame) that are upstream and downstream of each other (Figure 4). As shown in Figure 5, the reconnection site is marked with a black circle and it occurs near the subsolar point of the magnetopause. Obviously, this is magnetopause reconnection and the plasma of the outflow region is faster than the downstream plasma. Therefore, the high-speed zone is caused by high-speed plasma in the outflow region of MR. The low-speed zone is downstream of the high-speed zone and the plasma of the low-speed zone is not affected by the outflow region.

The structure is composed of a low-speed and high-speed zone, which are upstream and downstream of each other, respectively; this plays a blocking role in the flow of the magnetosheath. When the particles of one region are faster than downstream, the plasma in the two regions is squeezed. Next, part of the upstream particles flow from the side and the other part of the upstream particles accumulate in this structure. This process is similar to the impact of the solar wind on the Earth's magnetosphere, since the particles flowing from the side can widen the bow shock. However, the bow shock in front of this special structure isn't widened. Therefore, an indentation is formed at the junction of the widened and non-widened bow shock. Figure 6 is a schematic diagram which explains the formation process of the shock indentation. When solar wind plasma passes through the bow shock, the flow direction and velocity of the plasma will change. The velocity is the smallest near the subsolar bow shock and increases along the flow direction, while the distribution of the plasma density in the magnetosheath is exactly the opposite: plasma density is the highest near the subsolar bow shock and de-

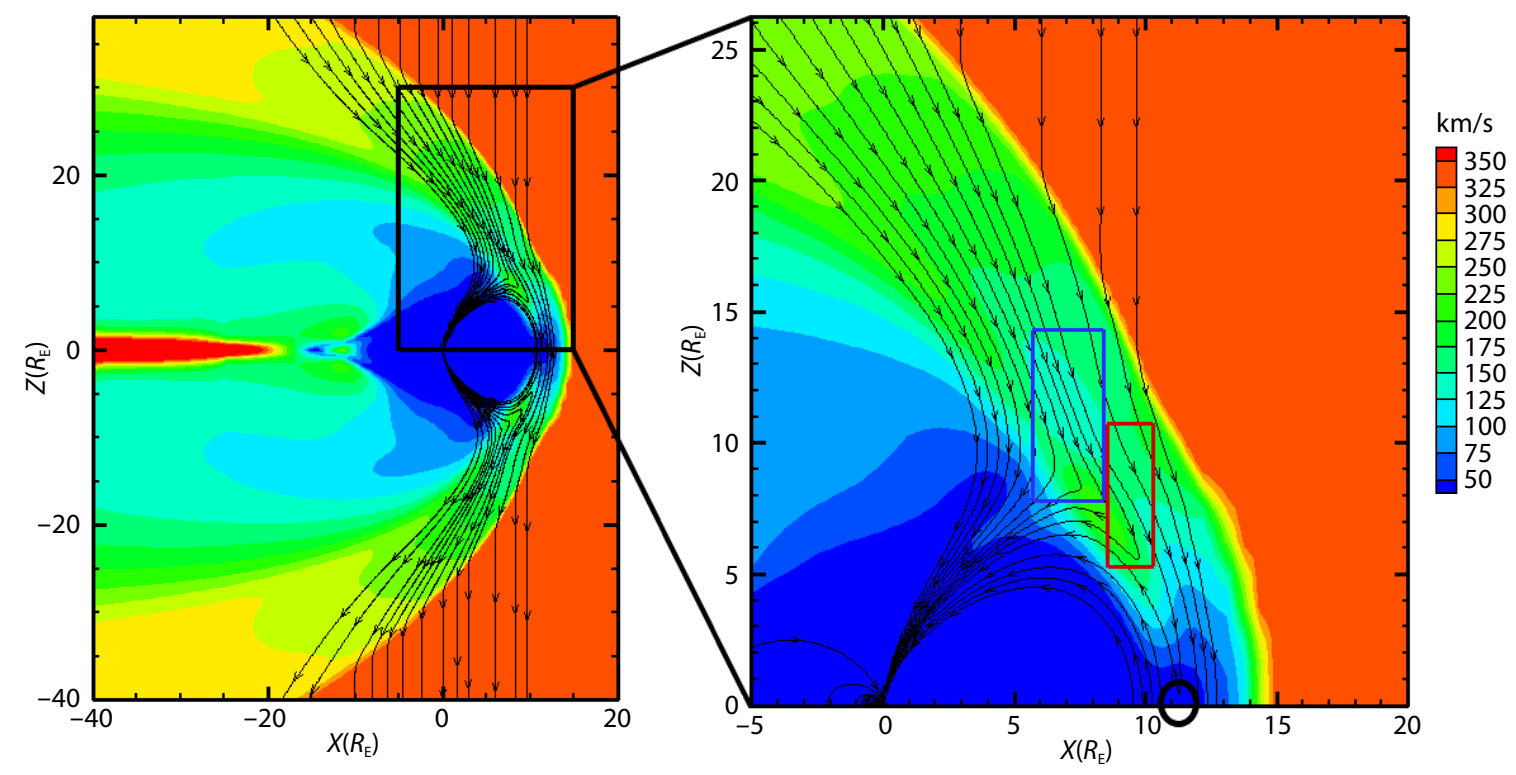

Figure 5. The plasma speed and magnetic field lines in the meridional plane under $B_{z}=-5 \mathrm{nT}$ and $P_{d}=1 \mathrm{nPa}\left(M_{\alpha}=7.08\right)$, in the same format as Figure 4.
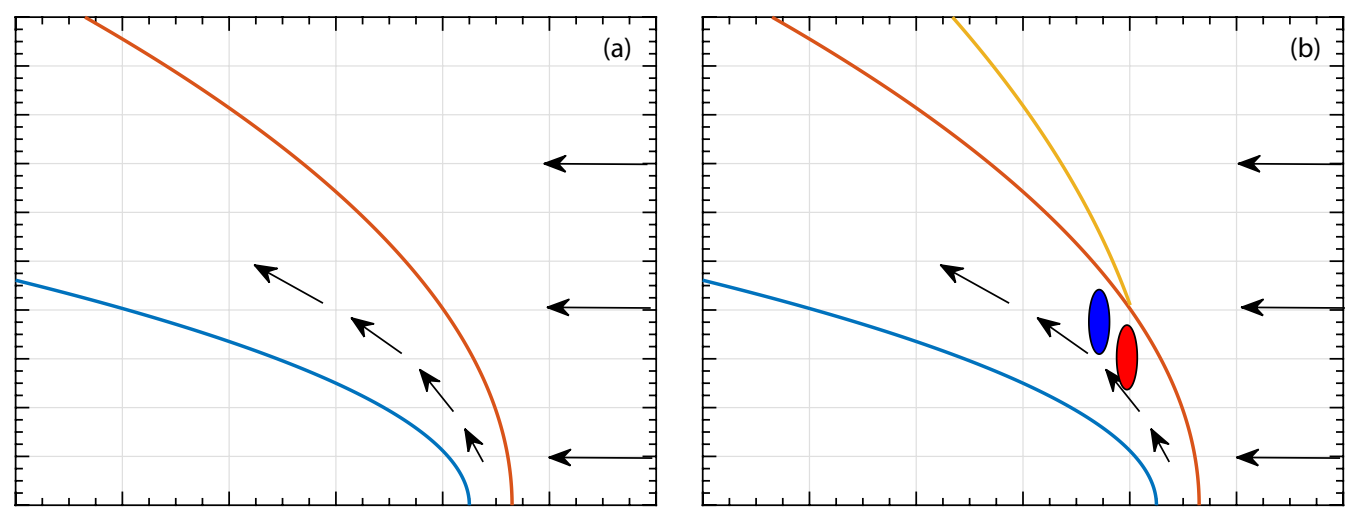

Figure 6. Schematic diagram of the indentation formation: (a) and (b) are before and after the formation of indentation, respectively. The blue line represents the position of the magnetopause. The red and yellow lines are the position of the bow shock. The arrows show the flow direction and its length represents the flow velocity. The red ellipse is the high-speed zone, and the blue ellipse is the low-velocity zone. 
creases with distance. Figure 6a shows the bow shock, magnetopause, and plasma flows before the formation of the high-speed zone and the low-speed zone. Figure $6 \mathrm{~b}$ shows that the original bow shock (red curve) begins to widen (yellow curve) due to the influence of the low-speed zone and high-speed zone. In addition, this structure will cause distortion of the magnetic field lines and accumulation of plasma in this area.

Figure 7 shows the plasma density and the flow direction in the $X Z$ plane under $B_{z}=-5 \mathrm{nT}$ and $P_{d}=1 \mathrm{nPa}$. The colored background indicates the density, and the arrow is the flow direction. In addition, the right panel of Figure 7 is an enlargement of the black frame in the left panel of Figure 7. The position and size of the red (blue) frames are the same in Figures. 3, 4, and 7. It can be found that there is a density accumulation, and the magnetic field lines are also distorted in this area. Thus we can confirm that the structure composed of the low-speed and high-speed regions is the direct cause of the indentation.

The conclusion of the bow shock indentation is as follows: when the IMF is southward and the $M_{a}$ is high (>5), the bow shock indentation can be clearly determined. Then, we further check the simulation results for other solar wind conditions and find that there is no indentation during northward IMF and at low $M_{\alpha}$. Figure 8 (Figure 9) shows the distribution of the plasma speed and flow direction (the magnetic field lines) in the $X Z$ plane under $B_{z}=$ $5 \mathrm{nT}$ and $P_{d}=1 \mathrm{nPa}$. The colored background displays $\left|V_{\text {total }}\right|$ which is $\sqrt{\left(V_{X}\right)^{2}+\left(V_{Z}\right)^{2}}$, and the right panel of Figure 8 (Figure 9) is an en-

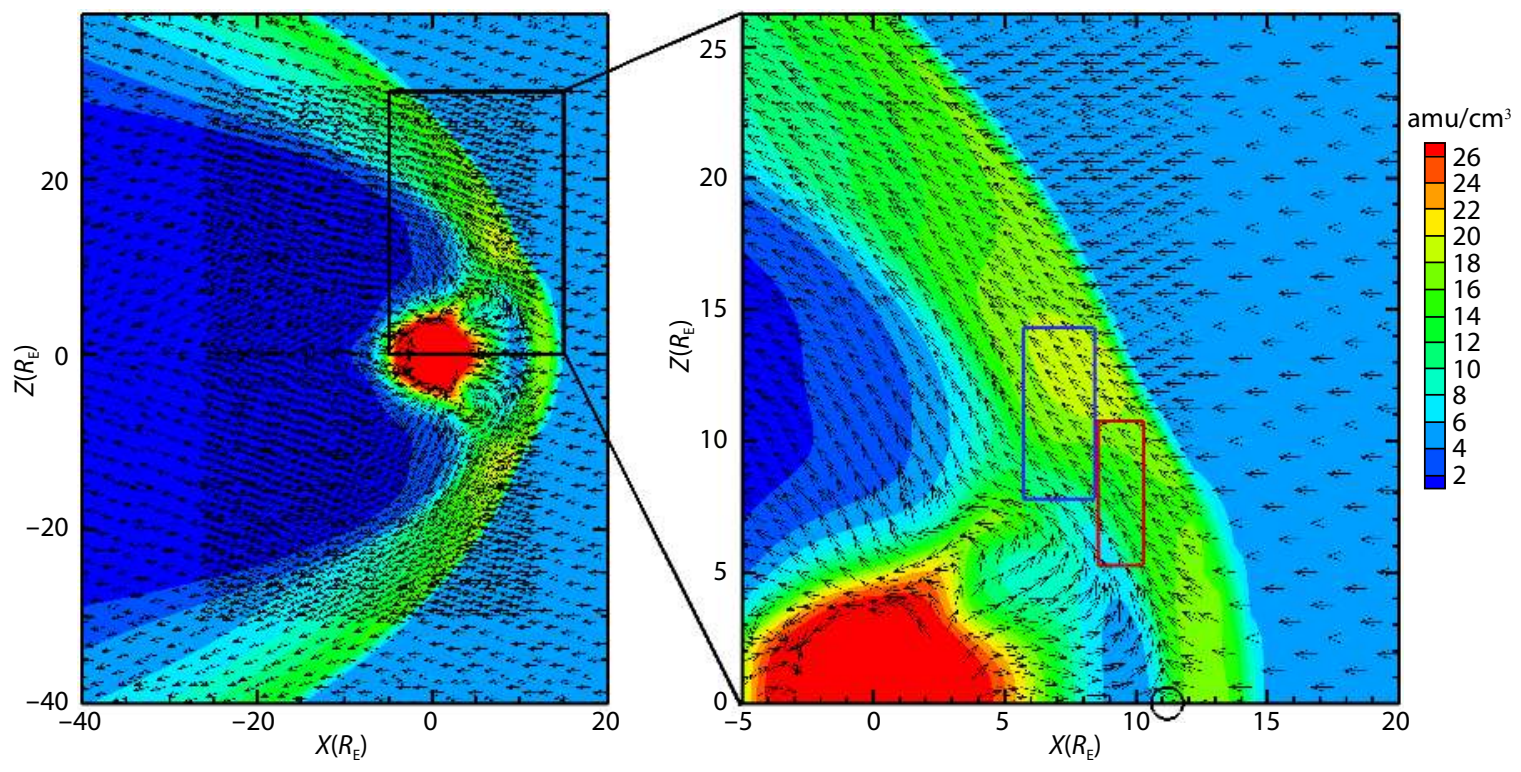

Figure 7. The density of plasma and flow direction in the meridional plane under $B_{z}=-5 \mathrm{nT}$ and $P_{d}=1 \mathrm{nPa}\left(M_{a}=7.08\right)$, in the same format as Figure 4.

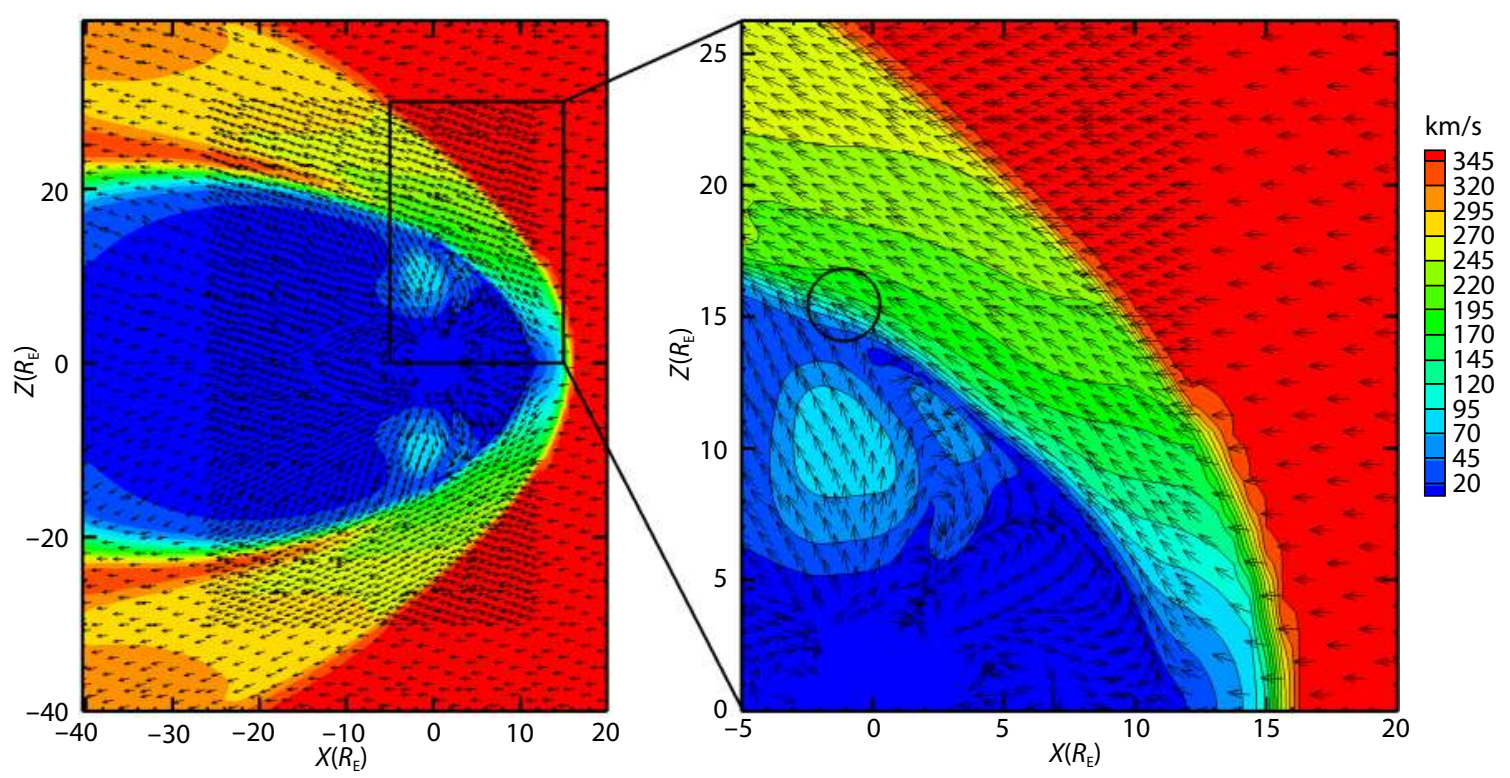

Figure 8. The plasma speed and flow direction in the meridional plane under $B_{z}=5 \mathrm{nT}$ and $P_{d}=1 \mathrm{nPa}\left(M_{\alpha}=7.08\right)$, in the same format as Figure 4 . 
largement of the black frame in the left panel of Figure 8 (Figure 9). From the distribution of magnetic field lines in Figure 9, it can be found that MR will occur at high latitudes, and an extreme velocity area is also formed in the outflow region. In the black frame in Figure 9, there are two extreme speed regions near $(X=0, Z=10)$ and $(X=3, Z=11)$. The former is related to the upflow particles above the polar region, and the latter is caused by the outflow region of MR. It can be seen from Figure 8 that the velocity of plasma is faster than upstream in the magnetosheath, which means that the outflow region of the high-latitude MR does not block the flow of the magnetosheath. Moreover, there is no high-speed zone and low-speed zone that are upstream and downstream of each other in the magnetosheath. This also leads to the phenomenon that the indentation exists when the IMF is southward, but not under the northward IMF. Comparing the plasma flow of the northward IMF with the southward IMF, it can be found that MR position has a great influence on bow shock indentation.

A similar process is performed with low $M_{a}$. Figure 10 (Figure 11) illustrates the plasma speed and flow direction (the magnetic field lines) in the $X Z$ plane under the southward IMF and low $M_{\alpha}$ (equal 3.54). The colored background denotes $\left|V_{\text {total }}\right|\left(\left|V_{\text {total }}\right|=\right.$ $\sqrt{\left(V_{X}\right)^{2}+\left(V_{Z}\right)^{2}}$ ) and the right panel of Figure 10 (Figure 11) is an enlargement of the black frame in the left panel of Figure 10 (Figure 11). It can be found that there is an extreme value of the flow velocity near $(X=8, Z=5.5)$ in Figure 10. As shown in Figure 11 , the extreme value area of the flow velocity is caused by the outflow region of MR. In Figure 10, we also find the high-speed zone (red frame) and low-speed zone (blue frame) are upstream and downstream of each other. The reason for the formation of

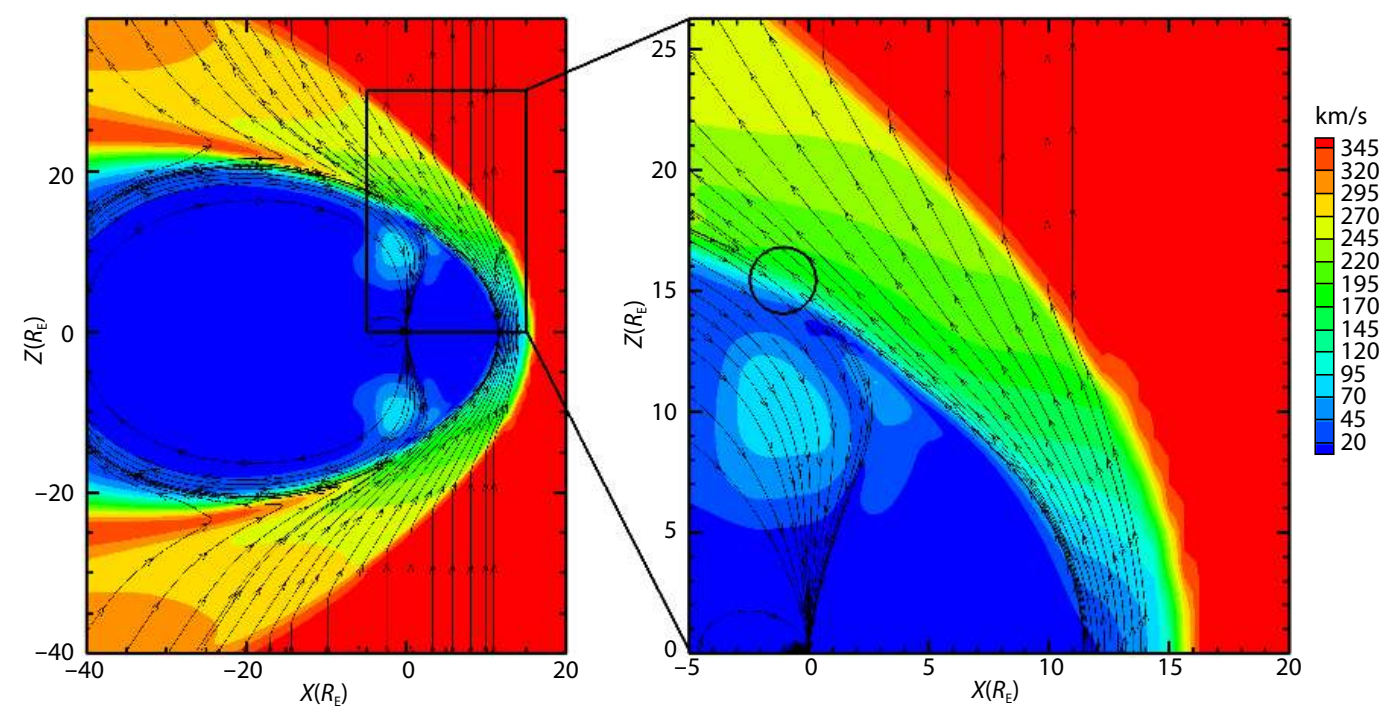

Figure 9. The plasma speed and magnetic field lines in the meridional plane under $B_{z}=5 \mathrm{nT}$ and $P_{d}=1 \mathrm{nPa}$, in the same format as Figure 5 .

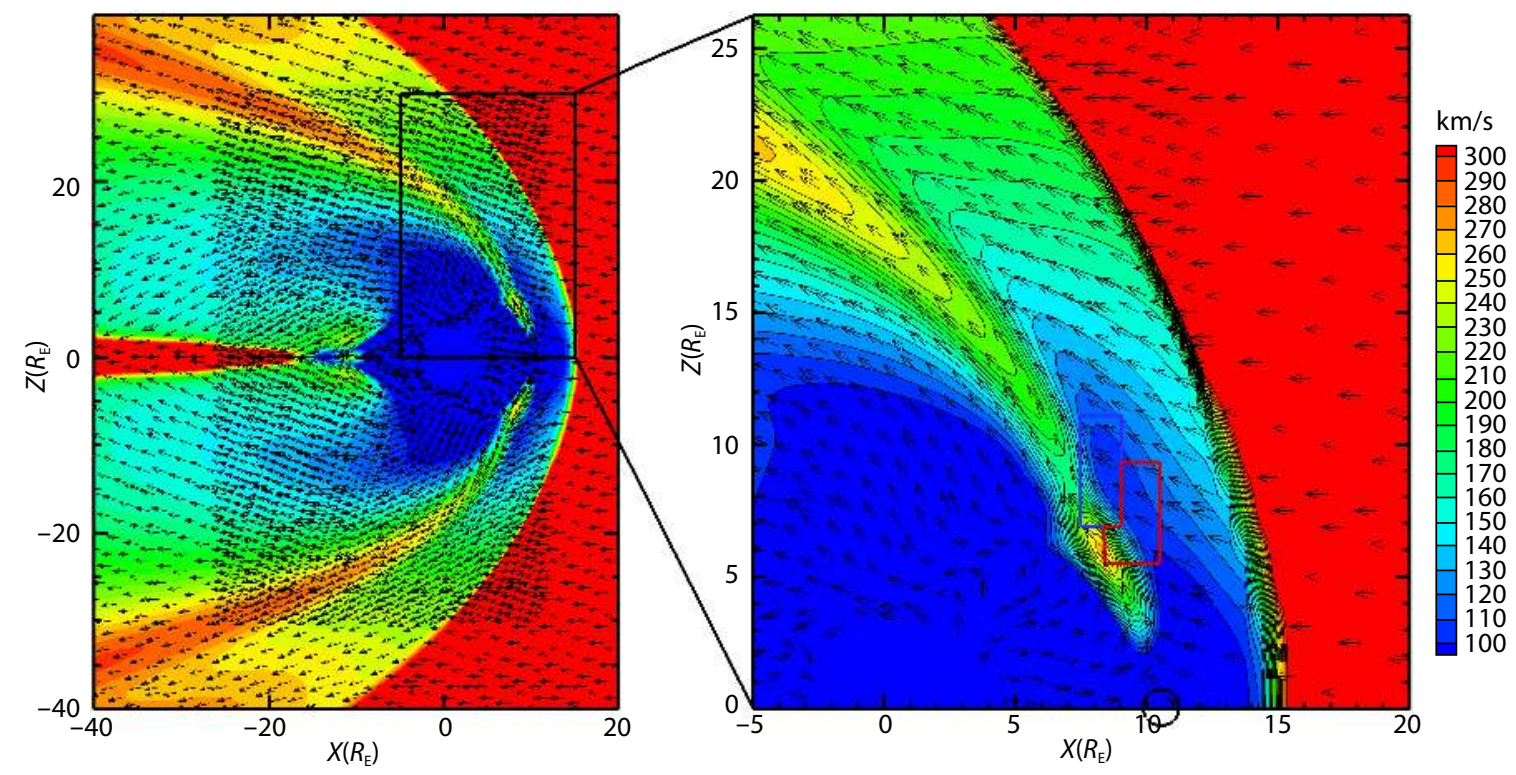

Figure 10. The plasma speed and flow direction in the meridional plane when IMF is southward and the Alfvén Mach number is 3.54 , in the same format as Figure 4. 


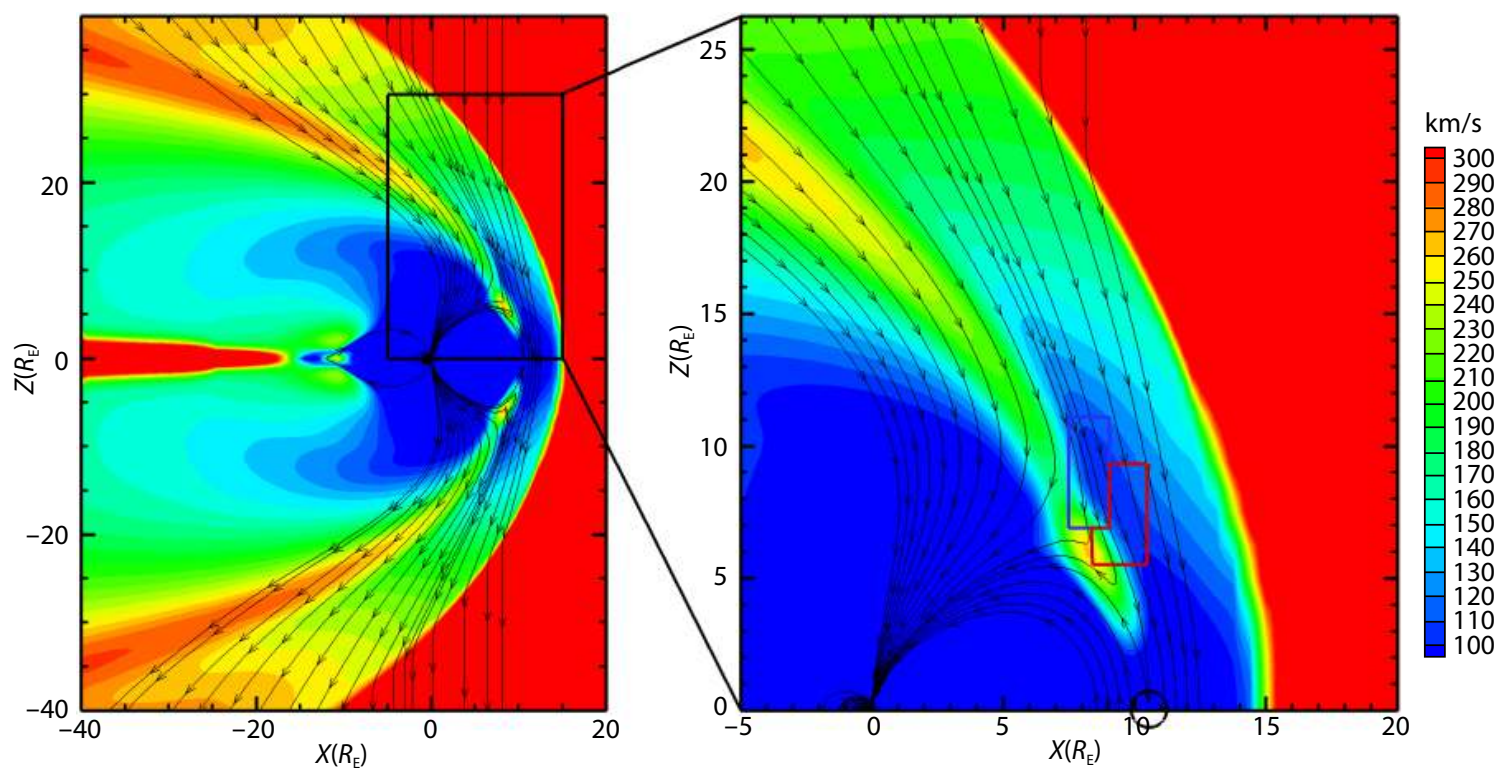

Figure 11. The plasma speed and magnetic field lines in the meridional plane when IMF is southward and the Alfvén Mach number is 3.54 , in the same format as Figure 5.

this high-speed zone includes two aspects: high-speed plasma in the outflow region of $M R$ and the thickening of the magnetosheath at low $M_{a}$. Comparing Figure 10 with Figure 4 , it is found that the structure composed of the high-speed zone and the low-speed zone is relatively weak (the difference of plasma speed between the high-speed zone and the low-speed zone is small and the range is small), when $M_{\alpha}$ is low. In addition, the position of this structure in Figure 10 is more biased toward the magnetopause, and the thickness of the magnetosheath will increase when $M_{a}$ becomes lower. Because of these factors, the hindering effect of this structure becomes smaller, resulting in the absence of a bow shock indentation.

\section{Summary and Conclusions}

The aim of the present research is to examine whether the bow shock has an indentation, and identify the formation conditions and physical mechanism of the bow shock indentation in the simulation results of the MHD model. The first extreme of plasma density slope is used as the criterion for position of the bow shock. Based on the formula of the magnetopause model by Shue $\mathrm{JH}$ et al. (1997), the parameters that can describe the flaring angle of the bow shock are obtained. The steep and large decrease of the flaring angle at low latitudes of the dayside is used as the criterion for determining the indentation. According to these criter$\mathrm{ia}$, the bow shock indentation under different solar wind conditions is analyzed statistically, and the formation processes of the bow shock indentation is studied. The results show that:

(1) The bow shock indentation corresponding to the cusp exists when the IMF is southward and the Alfvén Mach number of the solar wind is high (>5). The high-speed plasma in the outflow region of MR occurring at low latitudes of the dayside magnetopause disturbs the original flow in the magnetosheath around the magnetopause, and forms a high-speed zone and a low-speed zone that are upstream and downstream of each other. This struc- ture acts as a hindrance, causing the bow shock behind the structure to widen and form an indentation within the original bow shock.

(2) When the IMF is southward and the Alfvén Mach number is low $(<3.5)$, the outflow region of MR that occurs at low latitudes does not have a serious impact on the flow inside the magnetosheath. In addition, the magnetosheath is thicker when the Alfvén Mach number is low. These two factors form a high-speed zone and low-speed zone with less hindrance, such that the bow shock indentation does not appear.

(3) When the IMF is northward, MR occurs at high latitudes and the outflow region does not block the original flow of the magnetosheath, thus there is no shock indentation.

This work confirms the existence of the bow shock indentation through the simulation results of the MHD model, and explains the physical mechanism of this indentation. Note that the simulation results are limited to zero dipole tilt and this conclusion may need to be validated using future observations.

\section{Acknowledgments}

The simulation results are provided by the SWMF (Space Weather Modeling Framework) developed by the Space Environment Modeling Center of the University of Michigan. This work was supported in part by the National Natural Science Foundation of China (grant 42030203, 42074195, and 41974190). The numerical calculations in this paper were performed using the Supercomputing Center of Nanjing University of Information Science \& Technology.

\section{References}

Cairns, I. H., and Lyon, J. G. (1995). MHD simulations of Earth's bow shock at low Mach numbers: Standoff distances. J. Geophys. Res., 100(A9), 17173-17180. https://doi.org/10.1029/95JA00993

Chao, J. K., Wu, D. J., Lin, C. H., Yang, Y. H., Yang, X. Y., Kessel, M., Chen, S. H., and Lepping, R. P. (2002). Models for the size and shape of the Earth's magnetopause and bow shock. COSPAR Colloq. Ser., 12, 127-135. 
https://doi.org/10.1016/S0964-2749(02)80212-8

Chapman, J. F., and Cairns, I. H. (2003). Three-dimensional modeling of earth's bow shock: shock shape as a function of Alfvén Mach number. J. Geophys. Res., 108(A5), SSH 1-1-SSH 1-10. https://doi.org/10.1029/2002JA009569

Cowley, S. W. H. (1981). Asymmetry effects associated with the x-component of the IMF in a magnetically open magnetosphere. Planet. Space Sci., 29(8), 809-818. https://doi.org/10.1016/0032-0633(81)90071-4

Dmitriev, A. V., Chao, J. K., and Wu, D. J. (2003). Comparative study of bow shock models using wind and geotail observations. J. Geophys. Res., 108(A12), SMP 24-1-SMP 24-19. https://doi.org/10.1029/2003JA010027

Fairfield, D. H. (1971). Average and unusual locations of the Earth's magnetopause and bow shock. J. Geophys. Res., 76(28), 6700-6716. https://doi.org/10.1029/JA076i028p06700

Farris, M. H., and Russell, C. T. (1994). Determining the standoff distance of the bow shock: Mach number dependence and use of models. J. Geophys. Res., 99(A9), 17681-17689. https://doi.org/10.1029/94JA01020

Formisano, V. (1979). Orientation and shape of the Earth's bow shock in three dimensions. Planet. Space Sci., 27(9), 1151-1161. https://doi.org/10.1016/0032-0633(79)90135-1

Gombosi, T. I., Dezeeuw, D. L., Groth, C. P. T., and Powell, K. G. (2000). Magnetospheric configuration for parker-spiral IMF conditions: results of a 3d amr mhd simulation. Adv. Space Res., 26(1), 139-149. https://doi.org/10.1016/S0273-1177(99)01040-6

Gonzalez, W. D., Joselyn, J. A., Kamide, Y., Kroehl, H. W., Rostoker, G., Tsurutani, B. T., and Vasyliunas, V. M. (1994). What is a geomagnetic storm?. J. Geophys. Res., 99(A4), 5771-5792. https://doi.org/10.1029/93JA02867

Hu, H. P., Lu, J. Y., Zhou, Q., Wang, M., Yang, Y. F., Liu, Z. Q., and Pei, S. X. (2015). Simulation of three-dimensional Earth's bow shock. Chin. J. Space Sci. (in Chinese), 35(1), 1-8. https://doi.org/10.11728/cjss2015.01.001

Jelínek, K., Němeček, Z., Šafránková., J., and Merka, J. (2008). Influence of the tilt angle on the bow shock shape and location. J. Geophys. Res., 113(A5), A05220. https://doi.org/10.1029/2007ja012813

Jelínek, K., Němeček, Z., and Šafránková, J. (2012). A new approach to magnetopause and bow shock modeling based on automated region identification. J. Geophys. Res., 117, A05208. https://doi.org/10.1029/2011JA017252

Jing, H., Lu, J. Y., Kabin, K., Zhao, J. S., Liu, Z. Q., Yang, Y. F., Zhao, M. X., and Wang, M. (2014). MHD simulation of energy transfer across magnetopause during sudden changes of the IMF orientation. Planet. Space Sci., 97, 50-59. https://doi.org/10.1016/j.pss.2014.04.001

Kabin, K., Rankin, R., Rostoker, G., Marchand, R., Rae, I J., Ridley, A. J., Gombosi, T. I., Clauer, C. R., and Dezeeuw, D. L. (2004). Open-closed field line boundary position: a parametric study using an MHD model. J. Geophys. Res., 109(A5), A05222. https://doi.org/10.1029/2003JA010168

Liu, Z. Q., Lu, J. Y., Kabin, K., Yang, Y. F., Zhao, M. X., and Cao, X. (2012). Dipole tilt control of the magnetopause for southward IMF from global magnetohydrodynamic simulations. J. Geophys. Res., 117(A7), A07207. https://doi.org/10.1029/2011JA017441

Liu, Z. Q., Lu, J. Y., Wang, C., Kabin, K., Zhao, J. S., Wang, M., Han, J. P., Wang, J. Y., and Zhao, M. X. (2015). A three-dimensional high Mach number asymmetric magnetopause model from global MHD simulation. J. Geophys. Res., 120(7), 5645-5666. https://doi.org/10.1002/2014JA020961

Lu, J. Y., Liu, Z. Q., Kabin, K., Zhao, M. X., Liu, D. D., Zhou, Q., and Xiao, Y. (2011). Three dimensional shape of the magnetopause: Global MHD results. J. Geophys. Res., 116(A9), A09237. https://doi.org/10.1029/2010JA016418

Lu, J. Y., Liu, Z. Q., Kabin, K., Jing, H., Zhao, M. X., and Wang, Y. (2013). The IMF dependence of the magnetopause from global MHD simulations. J. Geophys. Res., 118(6), 3113-3125. https://doi.org/10.1002/jgra.50324

Lu, J. Y., Yuan, H. Z., Wang, M., and Yang, Y. F. (2017). Dipole tilt controls bow shock location and flaring angle. Sci. China Earth Sci., 60(1), 198-206. https://doi.org/10.1007/s11430-015-0268-8

Lu, J. Y., Zhou, Y., Ma, X., Wang, M., Kabin, K., and Yuan, H. Z. (2019a). Earth's bow shock: A new three-dimensional asymmetric model with dipole tilt effects. J. Geophys. Res., 124(7), 5396-5407. https://doi.org/10.1029/2018JA026144
Lu, J. Y., Zhang, H. X., Wang, M., Gu, C. L., and Guan, H. Y. (2019b). Magnetosphere response to the IMF turning from north to south. Earth Planet. Phys., 3(1), 8-16. https://doi.org/10.26464/epp2019002

Merka, J., and Szabo, A. (2004). Bow shock's geometry at the magnetospheric flanks. J. Geophys. Res., 109(A12), A12224.

https://doi.org/10.1029/2004JA010567

Merka, J., Szabo, A., Slavin, J. A., and Peredo, M. (2005). Three-dimensional position and shape of the bow shock and their variation with upstream Mach numbers and interplanetary magnetic field orientation. J. Geophys. Res., 110(A04), A04202. https://doi.org/10.1029/2004JA010944

Němeček, Z., and Šafránková, J. (1991). The Earth's bow shock and magnetopause position as a result of the solar wind-magnetosphere interaction. J. Atmos. Terr. Phys., 53(11-12), 1049-1054. https://doi.org/10.1016/0021-9169(91)90051-8

Peredo, M., Slavin, J. A., Mazur, E., and Curtis, S. A. (1995). Three-dimensional position and shape of the bow shock and their variation with Alfvénic, sonic and magnetosonic Mach numbers and interplanetary magnetic field orientation. J. Geophys. Res., 100(A5), 7907-7916. https://doi.org/10.1029/94ja02545

Rae, I. J., Kabin, K., Lu, J. Y., Rankin, R., Milan, S. E., Fenrich, F. R., Watt, C. E. J., Zhang, J. C., Ridley, A. J., ... DeZeeuw, D. L. (2010). Comparison of the openclosed separatrix in a global magnetospheric simulation with observations: the role of the ring current. J. Geophys. Res., 115(A8), A08216. https://doi.org/10.1029/2009ja015068

Shi, Q. Q., Zong, Q.-G., Zhang, H., Pu, Z. Y., Fu, S. Y., Xie, L., Wang, Y. F., Chen, Y., Li, L., ...Lucek, E. (2009). Cluster observations of the entry layer equatorward of the cusp under northward interplanetary magnetic field. J. Geophys. Res., 114(A12), A12219. https://doi.org/10.1029/2009JA014475

Shi, Q. Q., Zong, Q. G., Fu, S. Y., Dunlop, M. W., Pu, Z. Y., Parks, G. K., Wei, Y., Li, W. H., Zhang , H., ... Lucek, E. (2013). Solar wind entry into the high-latitude terrestrial magnetosphere during geomagnetically quiet times. Nat. Commun., 4(1), 1466. https://doi.org/10.1038/ncomms2476

Shi, Q. Q., Hartinger, M. D., Angelopoulos, V., Tian, A. M., Fu, S. Y., Zong, Q. G., Weygand, J. M., Raeder, J., Pu, Z. Y., ... Shen, X. C. (2014). Solar wind pressure pulse - driven magnetospheric vortices and their global consequences. J. Geophys. Res., 119(6), 4274-4280. https://doi.org/10.1002/2013JA019551

Shue, J. H., Chao, J. K., Fu, H. C., Russell, C. T., Song, P., Khurana, K. K., and Singer, H. J. (1997). A new functional form to study the solar wind control of the magnetopause size and shape. J. Geophys. Res., 102(A5), 9497-9511. https://doi.org/10.1029/97JA00196

Song, P., DeZeeuw, D. L., Gombosi, T. I., Groth, C. P. T., and Powell, K. G. (1999). A numerical study of solar wind-magnetosphere interaction for northward interplanetary magnetic field. J. Geophys. Res., 104(A12), 28361-28378. https://doi.org/10.1029/1999JA900378

Song, P., DeZeeuw, D.L., Gombosi, T.I., Kozyra, J.U., Powell, K.G. (2001). Global MHD simulations for southward IMF: a pair of wings in the flanks. Adv. Space Res., 28(12), 1763-1771. https://doi.org/10.1016/S0273-1177(01)00544-0

Spreiter, J. R., Summers, A. L., and Alksne, A. Y. (1966). Hydromagnetic flow around the magnetosphere. Planet. Space Sci., 14, 223-253. https://doi.org/10.1016/00320633(66)90-124-3

Tóth, G., Sokolov, I. V., Gombosi, T. I., Chesney, D. R., Clauer, C. R., De Zeeuw, D. L., Hansen, K. C., Kane, K. J., Manchester, W. B., ... Kóta, J. (2005). Space weather modeling framework: a new tool for the space science community. J. Geophys. Res., 110(A12), A12226. https://doi.org/10.1029/2005JA011126

Tóth, G., Zeeuw, D. L. D., Gombosi, T. I., Manchester, W. B., Ridley, A. J., Sokolov, I. V., and Roussev, I. (2007). Sun-to-thermosphere simulation of the 28-30 october 2003 storm with the space weather modeling framework. Space Weather, 5(6), S06003. https://doi.org/10.1029/2006SW000272

Verigin, M. I., Kotova, G. A., Slavin, J., Szabo, A., Kessel, M., Safrankova, J., Němeček, Z., Gombosi, T. I., Kabin, K., ... Kalinchenko, A. (2001a). Analysis of the 3-d shape of the terrestrial bow shock by interball/magion 4 observations. Adv. Space Res., 28(6), 857-862. https://doi.org/10.1016/S0273-1177(01)00502-6

Verigin, M., Kotova, G., Szabo, A., Slavin, J., Gombosi, T., Kabin, K., Shugaev, F., and Kalinchenko, A. (2001b). Wind observations of the terrestrial bow shock: 
3-D shape and motion. Earth Planets Space., 53(10), 1001-1009. https://doi.org/10.1186/BF03351697

Wang, J., Guo, Z. F., Ge, Y. S., Du, A. M., Huang, C., and Qin, P. F. (2018). The responses of the earth's magnetopause and bow shock to the IMF Bz and the solar wind dynamic pressure: a parametric study using the AMR-CESEMHD model. J. Space Weather Space Clim., 8(A41).

https://doi.org/10.1051/swsc/2018030

Wang, J., Huang, C., Ge, Y. S., Du, A., and Feng, X. (2020). Influence of the IMF BX on the geometry of the bow shock and magnetopause. Planet. Space Sci., 182, 104844. https://doi.org/10.1016/j.pss.2020.104844

Wang, M., Lu, J. Y., Yuan, H. Z., Kabin, K., Liu, Z. Q., Zhao, M. X., and Li, G. (2015). The dipole tilt angle dependence of the bow shock for southward IMF: MHD results. Planet. Space Sci., 106, 99-107. https://doi.org/10.1016/j.pss.2014.12.002

Wang, M., Lu, J. Y., Kabin, K., Yuan, H. Z., Ma, X., Liu, Z. Q., Yamh, Y. F., Zhao, J. S., $\mathrm{Li}, \mathrm{G}$. (2016). The influence of IMF clock angle on the cross section of the tail bow shock. J. Geophys. Res., 121(11), 11077-11085.
https://doi.org/10.1002/2016JA022830

Wang, M., Lu, J. Y., Kabin, K., Yuan, H. Z., Liu, Z. Q., Zhao, J. S., and Li, G. (2018). The influence of IMF B-y on the bow shock: observation result. J. Geophys. Res., 123, 1915-1926. https://doi.org/10.1002/2017JA024750

Xiong, M., Peng, Z., Hu, Y. Q., and Zheng, H. N. (2009). Response of the Earth's magnetosphere and ionosphere to solar wind driver and ionosphere load: results of global MHD simulations. Chin. Phys. Lett., 26(1), 015202. https://doi.org/10.1088/0256-307x/26/1/01520

Zong, Q. G., Fritz, T. A., Zhang, H., Korth, A., Daly, P. W., Dunlop, M. W., Glassmeier, K. H., Reme, H., and Balogh, A. (2004). Triple cusps observed by cluster-temporal or spatial effect?. Geophys. Res. Lett., 31(9), L09810. https://doi.org/10.1029/2003GL019128

Zong, Q. G., and Zhang, H. (2018). In situ detection of the electron diffusion region of collisionless magnetic reconnection at the high-latitude magnetopause. Earth Planet. Phys., 2(3), 231-237.

https://doi.org/10.26464/epp2018022 